\title{
Adoption of Cloud Computing in Manufacturing Industry Supply Chains, A Hype or a Myth?
}

\author{
Ali, Syed Imran
}

Computer \& Information Technology Department, King Fahd University of Petroleum \& Minerals Dhahran, Saudi Arabia.

\begin{abstract}
Cloud computing technology which is next-generation architecture has created hype in IT and business world promising to deliver wide range of benefits. Gartner estimated that cloud market will surpass $\$ 148.8$ billion by 2014. Despite the fact cloud computing technology remains for many an unfamiliar concept. Therefore, if cloud computing technology is to achieve its potential then there is need to have a clear understanding of various factors associated with its adoption by business. Cloud computing technology has already started impacting businesses and penetrated many areas from banks, automobile sector, education, logistics, wholesale, retail and health care. It is also emerging as a major enablers for the manufacturing industry that can transform the traditional business model, help it with product innovation with business strategy and create effective factory networks with collaboration. Adoption of cloud computing technology in supply chains of manufacturing industry will also improve performance in the form of better information visibility, cost reduction, and improved agility. For IS researchers, this study will outline factors associated with adaption of cloud computing technology in supply chains of manufacturing industry so that they will be in a position to advise the industry in the years to come. .

The paper will start by general introduction with an overview about cloud computing. Then, it will summarize the literature work that has been done so far with advantages of cloud computing technology. In next section, the theoretical framework will be described. Finally, the paper will close with a conclusion.
\end{abstract}

Keywords: Cloud Computing,Supply Chain Performance, Manufacturing indutsry, Cloud computing technology (CCT), Adoption.

\section{INTRODUCTION}

Cloud Computing is a new trend that discloses the next-generation architecture (Hutchison et al., 2009). This architecture represents a major change in the way information technology (IT) services are invented, developed, deployed, maintained and paid for (Sean et al.,2011).Gartner estimated that cloud market will surpass $\$ 148.8$ billion by 2014 (Christy et al., 2012). Despite the fact cloud computing technology remains for many an unfamiliar concept. Therefore, if cloud computing is to achieve its potential then there is need to have a clear understanding of the factors that can influence its adoption in business.

There is growing recognition that excellent supply chain performance has strategic value that could lead to; rapid financial payback; improvements in productivity and profits; improvements in customer positioning ; product quality; and enhancements in long-term relationships with suppliers (Attaran, M. and Attaran, S., 2007).Cloud computing technology (CCT) has already started impacting businesses and penetrated many areas from banks, automobile sector, education, logistics, wholesale, retail and health care (Al-Hudhaif et al., 2011). Cloud computing is also emerging as a major enablers for the manufacturing industry; it can transform the traditional business model, help it with product innovation with business strategy and create effective factory networks with collaboration (Xun Xu, 2012). Adoption of CCT will improve performance in the form of better information visibility, cost reduction, improved agility, resource management and greater flexibility (Angela et al, 2012). Its adoption in manufacturing industry is less understood. This has created a knowledge gap.

This research is an effort to fill this knowledge gap. It is imperative to study to what extent CCT is being adopted by manufacturing industries to improve supply chain performance and what are the factors that help or hinder its adoption. Manufacturing industry is chosen because the business in this industry is becoming increasingly IT-resilient, globalized, distributed and agile demanding (Xuan $\mathrm{Xu}, 2012$ ). These are the motivations which form the basis for this research. 


\section{International Journal of Enhanced Research in Science Technology \& Engineering, ISSN: 2319-7463 Vol. 2 Issue 7, July-2013, pp: (29-33), Available online at: www.erpublications.com}

\section{LITERATURE REVIEW}

Extreme market competition and a dynamic business environment tends the organizations to adopt various high-tech information technologies to improve their business operations (Pan and Jang, 2008; Sultan, 2010). In recent years, the term "cloud computing" has been critical in the world of IT. Cloud Computing Technology (CCT) has attracted much attention in both commercial and academic area. Cloud computing is not a new concept, it can be traced back to 1997, when it was first mentioned but recently it has become a fashionable or buzz term (Lijun et al., 2008). The term 'cloud' typically points to large pool of usable resources such as hardware and software that are easily accessible via the internet (Vaquero, 2009, Vouk, 2008).Characteristics of cloud computing somewhat similar to network computing, grid computing, utility computing, pervasive computing and service computing (Voas \& Zhang, 2009).CCT is a cloud-based architecture which is regulated by the supply and demand resources at market equilibrium (Buyya et al., 2008); its flexibility in terms of services usage (Vaquero, 2009); and pay as per usage of resources (Leavitt, 2009).

CCT represents two major developments in information technology (IT):

- IT efficiency, where power of computers is utilized efficiently by the use of highly scalable hardware and software resources (Sean et al.,2011).

- Business agility, where rapid deployment could be made as a competitive tool to respond to real time user requirements (W.Kim, 2009)

The concept of IT efficiency in CCT is actually encapsulated in green computing, where not only are the computing resources used more efficiently, but further, the computers can be physically located in geographical areas that have access to cheaper electricity (Sean et al.,2011). Business agility entails, cloud computing technology is not just cheap - but also a computational tool in business which could be deployed and scaled rapidly, thus reducing the need for huge upfront investment in enterprise IT (Sean et al.,2011).

\section{A. Advantages of Cloud Computing Technology CCT)}

There are several advantages but the salient ones are:

CCT dramatically lowers the cost of entry for smaller and medium size companies. They can benefit from the computing power for a relatively short amount of time (Sean et al.,2011). Reduction in capital investment in hardware and software infrastructure could therefore provide companies with the opportunity to acquire IT capacities that were not possible in past (Grossman, 2009).

CCT can lower IT barriers to innovation e.g. facebook and youtube (Sean et al.,2011).

Resource management is easier in enterprises by the use of CCT (Sean et al.,2011). Since computing resources are managed through software as a service (SaaS), they can be deployed very fast which bring ease of use and financial benefit (Angela et al,2012).

Platform as a service (PaaS) provides a agile development environment that makes it easier to develop applications quickly and adopt them instantly (Angela et al,2012).It eliminates the wait for deployment of suitable hardware and software for the application (Greer,2009, Vile \& Liddle,2009)

From a business point of view, firms are increasingly attempting to integrate business processes into their existing IS applications and build internet-based technologies for transacting business with trading partners (Tuncay, 2010). In high-tech industries, ubiquitous data transformation practices have become one of the key aspects for improving operation efficiency. To enhance competitive advantage, developing cloud computing capability is an important undertaking because it is not only rapidly changing the way that enterprises buy, sell, and deal with customers, but it is also becoming a more integral part of enterprises' business tactics (Pyke, 2009). CCT diffusion becomes a significant research topic because it enables firms to execute data transactions along value chain activities (e.g. including manufacturing, finance, distribution, sales, customer service, information sharing and collaboration with trading partners) ( Pyke, 2009).

\section{B. Previous Research on Adoption of cloud computing technology}

Previous studies in CCT have shed light on the areas of new technologies, security requirement and future expectations in emerging environment. From the financial point of view, Misra and Mondal (2010) built two types of business models for companies willing to adopt CCT. There are business models for companies with an existing IT infrastructure and business models for startup companies. Prior studies have also indicated that technology can lead to higher profits. Misra and Mondal 


\section{International Journal of Enhanced Research in Science Technology \& Engineering, ISSN: 2319-7463 Vol. 2 Issue 7, July-2013, pp: (29-33), Available online at: www.erpublications.com}

(2010) tried to explain it further with a model that not only helps to identify the suitability of a company for cloud computing by clearly tracing all the factors but also tries to give a certain profitability assessment of the benefits associated with CCT. Banerjee (2009) provides an overview of technological research studies that were performed in HP labs and that adopted cloud-scale smart environments, such as utility computing and the smart data centre. Buyya et al. (2009) have also dealt with market-oriented resource allocation of cloud computing by leveraging third-generation Aneka enterprise grid technology. Grossman et al. (2009) developed a cloud-based infrastructure that had been optimised for performance networks and supported necessary data mining applications.

The future of computing lies in CCT, whose major goal is reducing the cost of IT services while increasing processing throughput, reliability, availability, and flexibility and decreasing processing time (Hayes, 2008). Though CCT promises to provide several strategic and operational advantages to its adopters; its adoption rate is not growing as expected (Banerjee, 2009; Buyya et al., 2009; Goscinski and Brock, 2010).

\section{THEORETICAL FRAMEWORK}

Business environment is characterized by pressure caused by stiff competition. The most successful competitors today are those who link their customers and suppliers together into tightly integrated networks. It requires a relentless search of new enterprise value propositions in order to deliver relationship-driven customer value propositions (Badii \& Sharif,2003). At the same time, many companies now realize that in order to have a global reach and local responsiveness, the traditional vertically integrated business model requires re-evaluation, with increased cooperation between partners (Edwards, Peters,\& Sharman, 2001) and sharing greater information with customer and suppliers (Ellinger, Taylor,\&Daugherty, 1999) in order to avoid interruptions in logistics flows (Svensson, 2001).

A.

\section{New Technology}

Cloud computing which is a new emerging technology provides a sound platform in this business agility. It helps in providing collaboration among companies, suppliers and customers. Certainly, collaborative companies are more successful than isolated companies (Daugherty et al., 2006). This buyer-supplier relationship is characterized by trust, commitment and long-term time horizons (Morris \& Carter, 2005).

"Cloud" is derived from the idea of businesses and users being able to access applications from anywhere in the world on demand. Cloud computing is defined as a collection of disembodied services accessible from anywhere using any mobile device with an internet-based connection (Erdogmus, 2009; Gartner, 2009; Misra and Mondal, 2010; Sultan, 2010). Surveys were completed in 2009 by Gartner analysts on IT trends (especially cloud computing) to show that cloud computing is being used more in the areas of business when compared to other fields (Gartner, 2009). There is no doubt about the paramount potential of cloud computing; according to a recent Merrill Lynch research note, cloud computing is expected to be a " $\$ 160$ billion addressable market opportunity, including $\$ 95$ billion in acquired business and productivity applications, and another $\$ 65$ billion in online advertising" (Hamilton, 2008).

There are three types of cloud deployment models.

A public cloud is characterized as being available from a third party service provider via the Internet, and is a cost-effective way to deploy IT solutions, especially for small or medium sized businesses. Google Apps is a prominent example of a public cloud that is used by many organizations of all sizes (Sean et. al.2011).

A private cloud offers many of the benefits of a public cloud computing environment, such as being elastic and service based, but is managed within an organization. Private clouds provide greater control over the cloud infrastructure, and are often suitable for larger installations. A private cloud can actually be handled by a third-party provider (Sean et. al.2011).

A hybrid cloud is a combination of a public and private cloud - typically, non-critical information is outsourced to the public cloud, while business-critical services and data are kept within the control of the organization (Sean et. al.2011). 


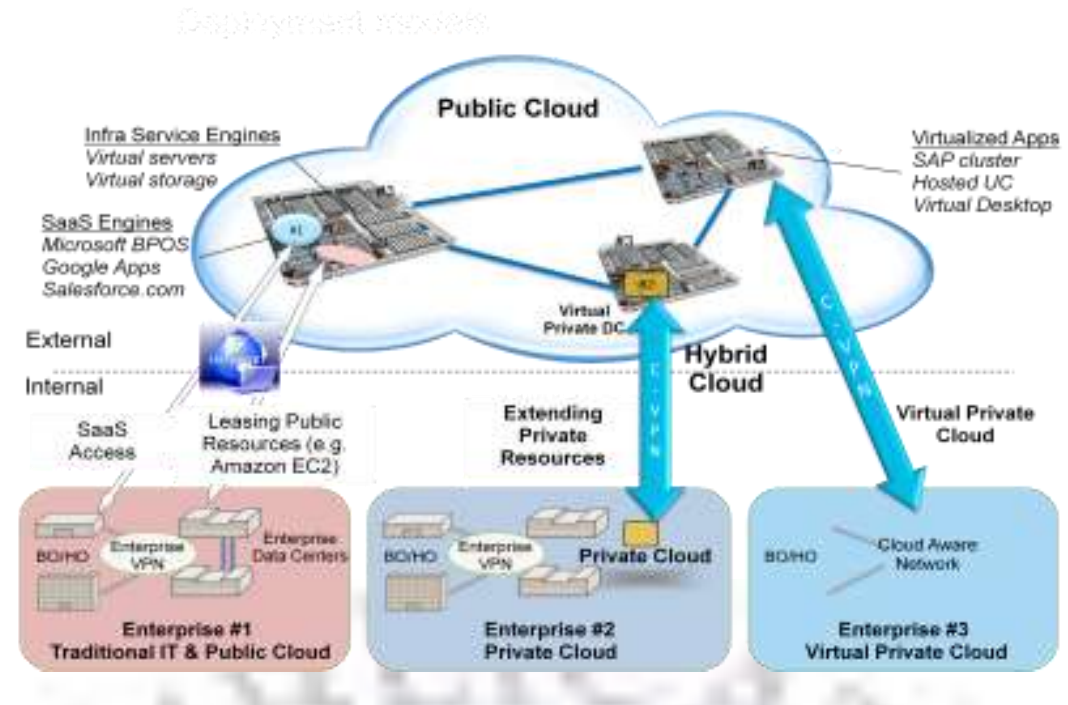

Figure 1: Public Cloud - (Chris,Ciena, 2011)

\section{CONCLUSION}

This paper has shown the author's viewpoint on the use of cloud computing in supply chains of manufacturing industries to improve performance. Cloud computing is used as a technology which has created hype in the technology world. Since there is no documented proof in the literature of the usage of cloud computing technology in supply chains of manufacturing industries; this would be the pioneering research in this area. As the name indicated cloud computing is created in the clouds without any boundaries and infrastructure. It is not just the ease of user to what accent he/she adopts it but to avail from the everlasting benefits of cloud computing. The important points that emerged out of the viewpoint are summarized in the following:

- Keeping in view the above points this research shows that extent of adoption of cloud computing technology in the manufacturing industries should be studied in more detail

- Contributing and impeding factors in adopting cloud computing technology by the manufacturing industries need to be studied

- Organizational factors impacting the degree of adoption of cloud computing technology by organizations/industries need to be explored further

- Cloud computing technology is helping in product innovation with business strategy but how it is effecting the manufacturing industry in agile environment, should need to be analyzed

\section{REFERENCES}

[1] Al-Hudhaif, S. and Alkubeyyer, A., (2011), "E-Commerce Adoption Factors in Saudi Arabia”, International Journal of Business and Management Vol. 6, No. 9, pp. 122-33.

[2] Attaran, M. and Attaran, S., (2007) "Collaborative supply chain management: The most promising practice for building efficient and sustainable supply chains", Business Process Management Journal, Vol. 13 Iss: 3, pp.390 - 404

[3] Angela Lin,Nan-Chou Chen, (2012). "Cloud computing as an innovation: Perception, attitude, and adoption ", International Journal of Information Management, http://dx.doi.org/10.1016/j.ijinfomgt.2012.04.001

[4] Banerjee, P. (2009), "An intelligent IT infrastructure for the future", Proceedings of 15th International Symposium on Highperformance Computer Architecture, HPCA, Raleigh, NC, USA.

[5] Buyya, R., Yeo, C. S., \& Venugopal, S. (2008). Market-oriented cloud computing: Vision, hype, and reality for delivering it services as computing utilities. In Proceeding of 10th IEEE international conference on high performance computing and communications Dalian, China, September, (pp. 5-13).

[6] Buyya, R., Yeo, C.S., Venugopa, S., Broberg, J. and Brandic, I. (2009), "Cloud computing and emerging it platforms: vision, hype, and reality for delivering computing as the 5th utility", Future Generation Computer Systems, Vol. 25, pp. 599-616.

[7] Chong, A.Y.L. and Ooi, K.B. (2008), "Adoption of inter-organizational system standards in supply chains: an empirical analysis of RosettaNet standards", Industrial Management \& Data Systems, Vol. 198, pp. 529-47. 


\section{International Journal of Enhanced Research in Science Technology \& Engineering, ISSN: 2319-7463 Vol. 2 Issue 7, July-2013, pp: (29-33), Available online at: www.erpublications.com}

[8] Christy Pettey, Ben Tudor. (2012). Gartner Says Worldwide Cloud Services Market to Surpass \$68 Billion in 2010.Retrieved July 17,2012 from http://www.gartner.com/it/page.jsp?id=1389313

[9] Chris C, Research and Marketing Strategies, The Research Bunker, What is Quantitative Research. Retrieved March 28,2012 from http://rmsbunkerblog.wordpress.com/2011/04/01/what-is-quantitative-research/

[10] Daugherty, P. J., Richey, R. G., Roath, A. S., Min, S., Chen, H., Arndt, A. D., \& Genchev,S. E. (2006). Is collaboration paying off for firms? Business Horizons, 49, 61-70.

[11] Erdogmus, H. (2009), “Cloud computing: does Nirvana hide behind the nebula?”, IEEE Software, Vol. 26, pp. 4-6.

[12] Gartner (2009), "Cloud computing inquiries at Gartner", available at: http://blogs.gartner.com/thomas_bittman/2009/10/29/cloudcomputing-inquiries-at-gartner (accessed 9 April 2012).

[13] Goscinski, A. and Brock, M. (2010), "Toward dynamic and attribute based publication, discovery and selection for cloud computing", Future Generation Computer Systems, Vol. 26, pp. 947-70.

[14] Greer, M. (2009). Software as a service inflection point: Using cloud computing to achieve business agility. New York: Global Authors Publishers.

[15] Grossman, R. (2009). The case for cloud computing. IT Professional, 11(2), 23-27.

[16] Grossman, R.L., Gu, Y.H., Sabala, M. and Zhang, W.Z. (2009), "Compute and storage clouds using wide area high performance networks", Future Generation Computer Systems, Vol. 25, pp. 179-83.

[17] Hamilton J. Internet-scale service efficiency. In: Large-Scale Distributed Systems and Middleware (LADIS) Workshop, September 2008. Available at: http://mvdirona.com/jrh/TalksAndPapers/JamesRH_Ladis2008.pdf.

[18] Hayes, B. (2008), "Cloud computing”, Communications of the ACM, Vol. 51, pp. 9-11.

[19] Hutchinson,C., Ward, J.,\&Castilion,K.(2009).Navigating the next-generation application architecture. IT Professional, 1(2), 18-22.

[20] Leavitt, N. (2009). Is cloud computing really ready for prime time? Computer, 42(1), 15-20.

[21] Lijun, M., Chan, W. K., \& Tse, T. H. (2008). A tale of clouds: Paradigm comparisons and some thoughts on research issues. In Proceeding of Asia-Pacific Services Computing Conference Yilan, Taiwan, (pp. 464-469).

[22] Misra, S.C. and Mondal, A. (2010), "Identification of a company's suitability for the adoption of cloud computing and modelling its corresponding return on investment", Mathematical and Computer Modelling, Vol. 53, pp. 504-21.

[23] Morris, M., \& Carter, C. R. (2005). Relationship marketing and supplier logistics performance: An extension of the key mediating variables model. The Journal of Supply Chain Management, 41, 32-43.

[24] Pyke, J. (2009), "Now is the time to take the cloud seriously", White Paper, available at: www.cordys.com/cordyscms_sites/objects/bb1a0bd7f47b1c91ddf36ba7db88241d/time_to_take_the_cloud_seroiusly_online_1_.pdf (accessed 9 November 2010).

[25] Sean Marston, Zhi Li,Subhajyoti.B,Juheng.Z,Anand.G(2011). Cloud Computing - The business prospective.Decision Support Systems 51 (2011) 176-189.

[26] Sultan, N. (2010), “Cloud computing for education: a new dawn?”, International Journal of Information Management, Vol. 30, pp. 109-16.

[27] Tuncay, E. (2010), "Effective use of cloud computing in educational institutions", Proscenia Social and Behavioral Sciences, Vol. 2, pp. 938-42.

[28] Vaquero, L. M., Rodero-Merino, L., Caceres, J., \& Lindner, M. (2009). A break in the clouds: Towards a cloud definition. Computer Communication Review, 39(1), 50-55.

[29] Vile, A., \& Liddle, J. (2009). The Savvy guide to HPC, grid, data grid, virtualization and cloud computing. The Savvy Guide To Ltd.

[30] Voas, J., \& Zhang, J. (2009). Cloud computing: New wine or just a new bottle? IT Professional, 11(2), 15-17.

[31] Vouk, M. A. (2008). Cloud computing-Issues, research and implementations. Journal of Computing and Information Technology, 16(4), 235-246.

[32] Pan, M.J. and Jang, W.Y. (2008), "Determinants of the adoption of enterprise resource planning within the technology-organizationenvironment framework: Taiwan's communications industry", Journal of Computer Information Systems, Vol. 48, pp.94-102.

[33] W. Kim, cloud computing: Today and Tomorrow, Journal of Object Technology 8 (1) (2009) 65-72

[34] Xuan Xu.(2012). From Cloud computing to Cloud Manufacturing. Robotics and Computer-Integrated Manufacturing 28(2012) 75-85. 